\title{
Reduction of Magnesium Corrosion Rate by PMMA-co-PMAA Films
}

\author{
Tayara C. Gonsalves ${ }^{a}$, Bruno X. de Freitas ${ }^{a}\left(\mathbb{1}\right.$, Carlos A. Nunes ${ }^{a}$, Fábio H. Florenzano ${ }^{a^{*}}$ \\ ${ }^{a}$ Universidade de São Paulo (USP), Escola de Engenharia de Lorena (EEL), Departamento de \\ Engenharia de Materiais, Lorena, SP, Brasil
}

Received: August 10, 2020; Revised: November 18, 2020; Accepted: December 13, 2020.

\begin{abstract}
Magnesium is an important base material for non-permanent implants, even though its corrosion rate in the human body is usually elevated for most applications. In order to reduce that rate, polymer coatings can be a better option than heavy-metal containing Mg alloys. In this work, random copolymers of PMMA and PMAA were synthesized and used for coating pure Mg by simply immersing $\mathrm{Mg}$ coupons into a diluted copolymer solution. It has been shown by SEM analysis and quantitative adsorption analysis that the copolymers have adsorbed onto the $\mathrm{Mg}$ surface. All the coated materials presented a lower corrosion rate than the uncoated $\mathrm{Mg}$, reaching close to $100 \%$ reduction for most of the copolymer up to 6 hours of testing. The copolymers with 5, 8 and 13\% of PMAA in their composition showed the best performances as corrosion controllers.
\end{abstract}

Keywords: Magnesium, Biomaterials, PMMA-co-PMAA, Corrosion, Polymer Coating.

\section{Introduction}

Magnesium is a bioabsorbable and biocompatible metal, however, its inadequate corrosion rate (too high) restrains wide application as temporary implants ${ }^{1}$. Nowadays, $\mathrm{Mg}$ alloys presents suitable corrosion rates, however, toxic elements such as rare earth elements and aluminum narrow their medical applications due to the release of toxic oxidized compounds ${ }^{2}$. In order to reduce the corrosion rate, polymer coatings are one of the most promising strategies to protect $\mathrm{Mg}$ and its alloys ${ }^{3-5}$. The presence of selected chemical groups in the polymers chains favors anchoring the polymer onto $\mathrm{Mg}$ surface and the formed film protects the metal just long enough to play its structural role and further be eliminated ${ }^{6}$.

Several examples of the use of polymer coating to reduce the corrosion rate of magnesium-based materials for biological applications can be found on the review published by Agarwal et al.in 2016 $6^{7}$. Despite the wide use of several polymeric materials as coatings, poly(methyl methacrylate)co-poly(methacrylic acid), PMMA-co-PMAA, to the best of our knowledge, have not been tested for corrosion protection of magnesium-based materials. This work presents a proofof-concept that such materials reduce the corrosion rate of pure magnesium and should be considered as an option for coating magnesium-based materials oriented to a biomaterial. Moreover, the procedure to manufacture the coating proposed here is quite simple what brings more interest over the system.

Polymethyl methacrylate (PMMA) has been used in bone cements for orthopedic applications and presents good biocompatibility with human tissues, however, its use as a polymer coating for $\mathrm{Mg}$ is still poorly investigated ${ }^{8,9}$. Jin et al. ${ }^{10}$ evaluated a PMMA spin coated in a ZK60 alloy and found that a PMMA film with a thickness of about $470 \mathrm{~nm}$ provides good protection against corrosive attack in simulated body fluids (SBF) and observed good cell adhesion as well as

*e-mail: fhfloren@usp.br cell viability. The applied coating method was spin coating and no information on the adhesion of the film to the metallic surface was provided. Mijamder and coworkers have used a chemical approach to attach silane to the surface of the AE42 alloy planned for coronary stents, after that a layer of PMMA was deposited. The corrosion rate was decreased and the material showed good biocompatibility ${ }^{11}$. None of those examples tested PMMA/PMAA copolymers.

Magnesium surface exposed to the regular atmosphere oxidizes and reacts promptly with humidity, generating $\mathrm{MgO}$ and $\mathrm{Mg}(\mathrm{OH})_{2}{ }^{12}$. The protective layer formed, particularly in aqueous media, is not stable due to the solubilization of $\mathrm{Mg}^{2+}$ at $\mathrm{pH}<12$ and to the presence of chloride ions, that replace the hydroxyl ions on the surface and makes the layer more water soluble ${ }^{13,14}$. On the other hand, $\mathrm{MgO}$ is prone to coordinate with several chemical groups such as carboxylic $\operatorname{acid}^{15,16}$, what opens an opportunity to create new polymeric coatings bearing such groups in order to provide good coating-surface interactions and, therefore, good adhesion.

In this work, poly(methyl methacrylate)-co-poly(methacrylic acid) copolymers, PMMA-co-PMAA, presenting several compositions, had their adsorption ability to $\mathrm{Mg}$ surface investigated along with their effects on decreasing $\mathrm{Mg}$ corrosion rate. The presence of an acidic repetitive unit (bearing $-\mathrm{COOH}$ ) was intended to enhance the interactions ${ }^{15}$ between the copolymer and the $\mathrm{MgO}$ layer formed when the surface is exposed to the air after polishing ${ }^{16}$, creating a more homogenous and stable coating. One interesting feature of this type of copolymer is that several characteristics of the material, such as the relative composition, molar mass, copolymer architecture, among others, can be changed in order to optimize the property one is looking for - coating formation and its efficiency, for instance.

Even though PMMA-co-PMAA is not considered biodegradable, it has been shown to present low (or none) 
toxicity ${ }^{17}$ and only a small quantity of the polymer bounded to the metal surface is necessary, what may allow the use of such material in medical applications. Furthermore, keeping the copolymer molecular weight below renal filtration threshold $(30-40 \mathrm{kDa})^{18}$ would allow the copolymer to be eliminate from the body via the urinary tract. The major goal here is to generate a promising type of coating for $\mathrm{Mg}$ that can be applied by a very easy and convenient procedure, such as dip coating.

\section{Materials and Methods}

All copolymers were synthesized by free radical polymerization. Five different contents of poly (methacrylic acid) were obtained by changing the initial monomer concentration ratios: $95 \%$ of methyl methacrylate: $5 \%$ methacrylic acid; 92:8; 90:10: 87:13 and 85:15. The reactivity ratio for those monomers are $\mathrm{rMMA}=0.55$ and $\mathrm{rMAA}=1.56^{19}$. A higher PMAA content is expected in the copolymers compared with the initial monomer concentration ratios. The monomers (Sigma-Aldrich) were passed through a column of basic alumina in order to remove the inhibitors. All syntheses were carried out at $70{ }^{\circ} \mathrm{C}$ using AIBN as initiator under argon atmosphere and magnetic stirring. The reaction was stopped when the solution became too viscous to be stirred (usually around $1 \mathrm{~h}$ ). The polymeric materials were then dried in an oven at $70{ }^{\circ} \mathrm{C}$.

All produced copolymers were characterized by FourierTransformed Infrared Spectroscopy (FTIR), Proton Nuclear Magnetic Resonance ( $\left.{ }^{1} \mathrm{H}-\mathrm{NMR}\right)$ and Gel Permeation chromatography (GPC). FTIR spectra were obtained in a Prestige 21 spectrophotometer (Shimadzu). Solutions of the copolymers in tetrahydrofuran (THF) were added to $\mathrm{KBr}$ pellets and dried for FTIR experiments. ${ }^{1} \mathrm{H}-\mathrm{NMR}$ was carried out in a Varian Mercury $300 \mathrm{MHz}$ spectrometer in deuterated chloroform. GPC was performed in a Shimadzu system equipped with two Phenomenex columns $\left(10^{4}\right.$ and $10^{5} \AA$ ). The elution solvent was THF with $0.3 \%$ triethylamine.

High purity magnesium (99.97\%) samples with $10 \times 10 \times 2 \mathrm{~mm}^{3}$ dimensions were ground up to $600 \#$ silicon carbide paper. The samples were ultrasonically cleaned in acetone for $10 \mathrm{~min}$, dried in air, and then coated by immersion in a copolymer concentration in THF solution followed by drying in air. Two different procedures were followed depending whether the sample would be used for surface characterization or corrosion rate studies. For surface characterization, only half of the sample was kept in contact with the solution $\left(10 \mathrm{mg} \mathrm{mL}^{-1}\right)$ in order to create a limit between coated and uncoated surface regions. For hydrogen evolution tests, the samples were completely immersed in a copolymer solution in THF $\left(2 \mathrm{mg} \mathrm{mL}^{-1}\right)$ for $24 \mathrm{~h}$.

The coated surfaces of the samples were silver coated $(15 \mathrm{~nm})$ and then analyzed using scanning electron microscope (SEM - Hitachi TM3000).

Quantitative adsorption was evaluated by measuring the equilibrium concentration of the copolymer solutions in THF after being in contact for 24 hours with standard magnesium pieces. The initial blank solution concentration (nominal) served as reference. GPC RI detector area ratio of the copolymer signal in sample and reference chromatograms was used to determine the equilibrium concentration after
$24 \mathrm{~h}\left(\mathrm{C}_{\mathrm{e}}\right)$, that was then used to calculate the mass of polymer adsorbed per area of metal $\left(\mathrm{q}_{\mathrm{e}}\right)$ according to Equation 1 .

$q_{e}=\left(C_{o}-C_{e}\right) /\left(v^{*}\right.$ area $\left._{M g}\right)$

where: $q_{e}$ is the amount of copolymer adsorbed per area of the sample

$\mathrm{C}_{0}$ is the copolymer nominal concentration before adsorption $\mathrm{C}_{\mathrm{e}}$ is the copolymer equilibrium concentration (after adsorption) $\mathrm{v}$ is the total volume of copolymer solution used area $_{\mathrm{Mg}}$ is the area of the $\mathrm{Mg}$ sample

For hydrogen evolution tests, coated and uncoated samples were immersed in a $0.9 \% \mathrm{NaCl}$ (wt.\%) aqueous solution and the evolved volume of hydrogen gas registered at room temperature via an inverted burette filled with the same saline solution. The corrosion of $\mathrm{Mg}$ is an electrochemical process, and, when immersed into a chloride solution, $\mathrm{Mg}$ reacts with water producing $\mathrm{Mg}(\mathrm{OH})_{2}$ on the surface and $\mathrm{H}_{2}$ gas is released. Each $\mathrm{Mg}$ atom oxidized to $\mathrm{Mg}^{2+}$ generates one hydrogen molecule so the volume of $\mathrm{H}_{2}$ produced at constant pressure and temperature is proportional to the mass of $\mathrm{Mg}$ oxidized. In water, chloride ions replace the hydroxyl on the metal surface producing a more soluble $\mathrm{MgCl}_{2}$. That is the reason why the corrosion of magnesium is faster in the biological media and in saline solutions (as the one used in this work in order to emulate some of the biological conditions). The following reactions summarize the corrosion process in salt water:

$$
\begin{aligned}
& \mathrm{Mg} \rightarrow \mathrm{Mg}^{2+}+2 e^{-} \\
& 2 \mathrm{H}_{2} \mathrm{O}+2 e^{-} \rightarrow \mathrm{H}_{2}+2 \mathrm{OH}^{-} \\
& \mathrm{Mg}^{2+}+2 \mathrm{OH}^{-} \rightarrow \mathrm{Mg}(\mathrm{OH})_{2} \\
& \mathrm{Mg}(\mathrm{OH})_{2}+2 \mathrm{Cl}^{-} \rightarrow \mathrm{MgCl}_{2}+2 \mathrm{OH}^{-}
\end{aligned}
$$

\section{Results and Discussion}

Five PMMA-co-PMAA copolymers of different MAA contents (5-15\%) were obtained in this work as white solids. The global reaction yields are shown in Table 1.

The average molar masses in Table 1 are within a broad range, which can be explained by the intrinsic reactivities as well as by other factors, such as gel effects. The PMMA-PMAA 95:05 presents the highest molar mass as well as the highest molar mass dispersivity index (Mw/Mn), probably because the reaction mix was more viscous in that case, particularly towards the end of the reaction which probably triggered gel effects.

The FTIR spectra of the materials exhibited the carbonyl signal (ester/carboxylic acid) at $1732 \mathrm{~cm}^{-1}$ and $\mathrm{OH}$ signal near $3500 \mathrm{~cm}^{-1}$, attributed to the $\mathrm{COOH}$ group, present in all copolymers. However, due to the hygroscopic behavior of these materials, it might be also associated to residual water.

The ${ }^{1} \mathrm{H}-\mathrm{NMR}$ data confirmed the molecular structure of the polymeric materials. The expected signals at 0.83/1.01 ppm $\left(\mathrm{C}-\mathrm{CH}_{3}\right) ; 1.81 / 1.94 \mathrm{ppm}\left(\mathrm{CH}_{2}\right) ; 3.59 \mathrm{ppm}$ $\left(\mathrm{O}-\mathrm{CH}_{3}\right)$ are observed ${ }^{20}$. PMMA-PMAA 95:05 1H-NMR 
Table 1. Syntheses yields and average molar masses (Mn, number averaged and $\mathrm{Mw}$, mass averaged).

\begin{tabular}{lcccc}
\hline \multicolumn{1}{c}{ Material } & Yield (\%) & Mw $(\mathrm{kDa})^{*}$ & $\mathrm{Mn}(\mathrm{kDa})^{*}$ & $\mathrm{Mw} / \mathrm{Mn}$ \\
\hline PMMA-PMAA 95:05 & 67.1 & 166 & 21.2 & 2.33 \\
\hline PMMA-PMAA 92:08 & 66.8 & 48.1 & 29.8 & 1.61 \\
\hline PMMA-PMAA 90:10 & 56.2 & 8.06 & 5.30 & 1.52 \\
\hline PMMA-PMAA 87:13 & 62.1 & 10.3 & 10.6 & 1.93 \\
\hline PMMA-PMAA 85:15 & 64.8 & 20.6 & & 1.94 \\
\hline * comparable to PMMA standards & & & &
\end{tabular}

was not acquired due to its low solubility in $\mathrm{CDCl}_{3}$. FTIR and $1 \mathrm{H}-\mathrm{NMR}$ are not presented, the authors can provide such data by request anytime.

Figure 1 presents an interface of coated and uncoated regions as well as details of the coated surfaces of magnesium samples obtained by immersion of part of the pieces in different copolymer solutions. The copolymers with lower contents of poly (methacrylic acid) show smoother surfaces than those of higher content.

The presence of PMAA in the materials was intended to increase the interaction with the magnesium surface since carboxyl polar groups with lone electron pairs can bind to metals $^{6}$. On the other hand, polar groups also increase the interpolymer interactions (internal hydrogen bonds) as well as hydrophilicity, what may be the reason for the alveolar patterns as seen on Figure $1 \mathrm{~h}$ and $\mathrm{j}$. Due to the hydrogen evolution results (see below), such alveolar patterns seem to be an upper layer on a more homogenous one, since both copolymers related to Figure $1 \mathrm{~h}$ and $\mathrm{j}$ have shown a good protective effect against corrosion. This would not be expected if the magnesium surface was in direct contact with the saline solution, even partially. The hypothesis here is that once the magnesium surface is completely coated, an upper layers builds up exhibiting this alveolar pattern. Since it is not expected that the copolymers present quasi-block or block architectures (not so different reactivity ratios), phase separation is not a plausible explanation for the pattern, since it is unlike to occur.

It is worth to note that all copolymers formed thin films on the samples by a very simple procedure (dip coating in a diluted solution).

Figure 2 shows the amount of polymer adsorbed when standard magnesium samples were immersed in the copolymers THF solutions. PMMA-PMAA 92:08 was not used for this test because it has presented solubility issues. The PMMAPMAA 85:15 stands out among the studied materials, with up to $5 \mu \mathrm{g}$ of copolymer adsorbed per $\mathrm{mm}^{2}$ of surface, all others reaching up to $3 \mu \mathrm{g}$ per $\mathrm{mm}^{2}$. Due to data scatter, the models tested to fit the data (Langmuir and Freundlich isotherm models) were not able to describe all the cases. Even though the GPC-based method is quite convenient and should be able to measure concentrations in the range of the $\mathrm{C}_{\mathrm{e}}$ values presented here, it is clear the low precision for the particular experimental conditions presented. For example, in Figure 2d, as GPC measures the remaining copolymer concentration after equilibrium, the lowest two $\mathrm{C}_{\mathrm{e}}$ values were determined to be quite similar and also close to the detection limit (high relative error). Because of that, $\mathrm{q}_{\mathrm{e}}$, that depends on $\mathrm{C}_{\mathrm{e}}$ according to equation 1, ended up to be quite different for those two concentrations, since $\mathrm{C}_{0}$ is also different for each sample. Besides such limitations, the method estimates well the amount of copolymer adsorbed on the surface taking into account the equilibrium concentrations $\left(\mathrm{C}_{\mathrm{e}}\right)$ altogether, although the points scatter hinders the build of a reliable isotherm adsorption graph. Also, in the case that the affinity of the copolymers to the $\mathrm{Mg}$ surface is quite high, $\mathrm{q}_{\mathrm{e}}$ are not considerably different comparing all the $\mathrm{C}_{\mathrm{e}}$ values since the adsorption plateau has been reached for this concentration range (surface saturated with copolymer even for the lowest concentrations used). That could be the reason why $\mathrm{q}_{\mathrm{e}}$ does not show any obvious trend with $\mathrm{C}_{\mathrm{e}}$, this hypothesis can be proved if lower $\mathrm{C}_{0}$ values are used, what is out of the scope of this work. Here, such tests were useful to estimate the magnitude of the copolymer mass per area unit on the Mg surface.

All coatings of different copolymers were able to decrease magnesium corrosion rates in saline solution as shown by the $\mathrm{H}_{2}$ evolution data in Figure 3. Classical saline solution ( $\mathrm{NaCl} 0.9 \%$, wt.\%) was chosen to provide the chloride ions present in biological fluids. As mentioned, $\mathrm{Cl}^{-}$plays a very important role in accelerating $\mathrm{Mg}$ corrosion in vivo ${ }^{12,21}$.

PMMA-PMAA 90:10 has shown to be the less effective coating, although it decreased the volume of evolved hydrogen by more than $80 \%$ after 5 hours, compared to uncoated magnesium. One explanation for the relatively low performance of this particular material probably relies on a low average molar mass combined with a relative high hydrophilicity $(10 \%)$, increasing the copolymer water solubility and leading to faster dissolution during the experiment. This find highlights the fact that hydrophilicity (composition) and molar mass can be both tuned simultaneously in order to reach maximum performance and adjust the corrosion rate as close as possible to the one needed.

The corrosion process of all other coated samples was suppressed by almost $100 \%$ over a 6 hours period, showing the potential of this simple coating technique to generate corrosion-protected magnesium. It is worth to mention that the material presenting the second lowest molar mass, PMMA-PMAA 87:13, of relative high hydrophilicity, showed the second worst surface protection. In this investigation, the protection mechanism was not directly accessed, however, it is expected that, as mentioned, a continuous film acts as a hydrophobic barrier on the surface of magnesium, decreasing the corrosion rate by controlling the water and ionic species access to the $\mathrm{Mg}$ surface.

In order to access to the most important factors for the corrosion protection presented on Figure 3, the relevant parameters of all materials studied are summarized on Table 2 .

As can be seen on Table 2, the two materials with the lowest molar mass are the ones that are less effective to 

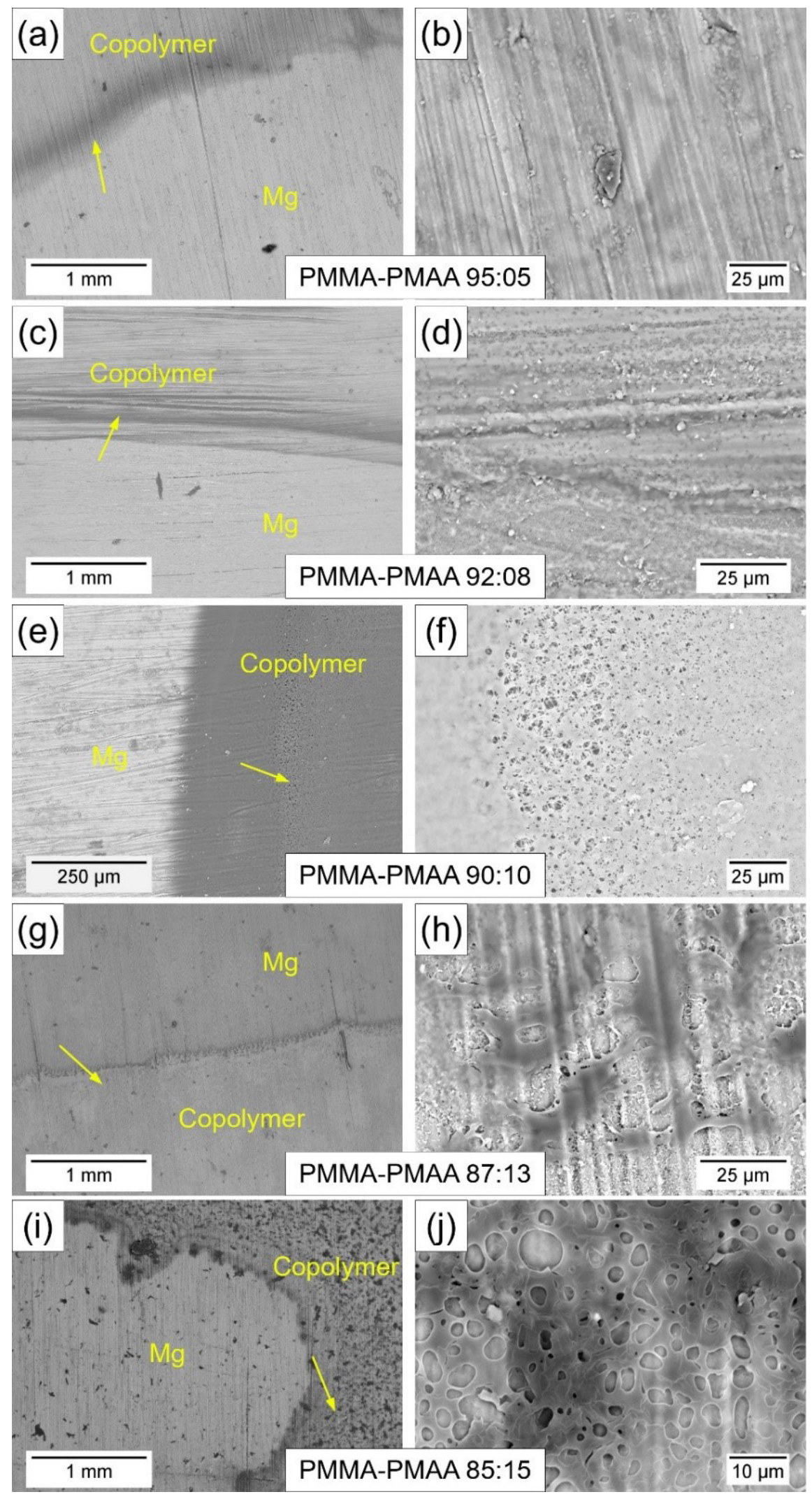

Figure 1. SEM/BSE micrographs of magnesium coupons where only half of the surfaces were immersed in copolymer THF solutions. Regions indicated by arrows are magnified on the correspondent images at right. The five materials are shown: photomicrographs a and b, PMMA-PMAA 95:05; $c$ and d, PMMA-PMAA 92:08; e and f, PMMA-PMAA 90:10; $g$ and h, PMMA-PMAA 87:13; i and j, PMMA-PMAA 85:15. 

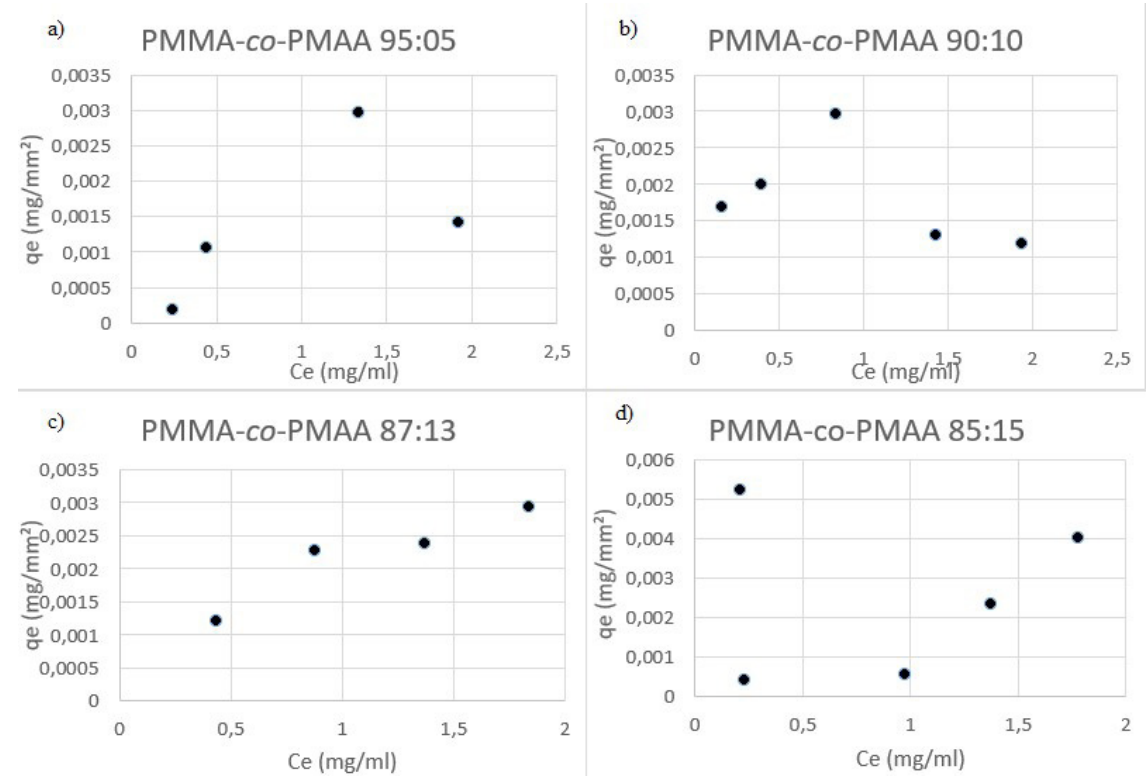

Figure 2. Adsorbed polymer mass per area $\left(\mathrm{q}_{\mathrm{e}}\right)$ as a function of the final equilibrium concentration $\left(\mathrm{C}_{\mathrm{e}}\right)$ : a) PMMA-PMAA 95:05; b) PMMA-PMAA 90:10; c) PMMA-PMAA 87:13; d) PMMA-PMAA 85:15.

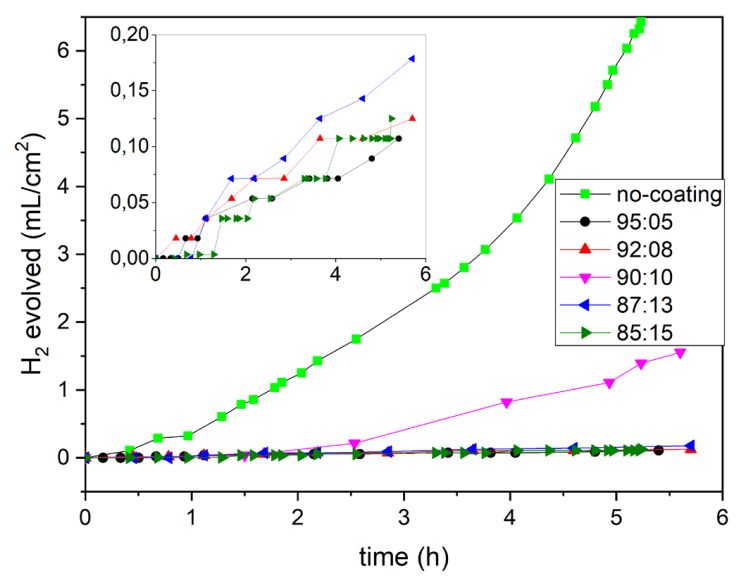

Figure 3. Hydrogen evolution due to magnesium corrosion for the coated and uncoated samples. Inset shows in detail the low $\mathrm{H}_{2}$ evolution of the most effective coating materials. Lines are to guide the eyes only.

avoid hydrogen emerging, even though the performance of PMMA-PMAA 87:13 is close to the most effective. The materials with the highest and the lowest hydrophobic content (95 and 85\%, respectively) are both very effective, suggesting that composition is not crucial for corrosion protection. On the other hand, the surface patterns observed on electron microscopy (Figure 1) seem to follow the order of hyphobicity, going from a smooth pattern for the most hydrophobic material to a "alveolar" pattern for the less hydrophobic one, in a continuous way. The pattern observed does not seem to correlate with the hydrogen evolution results.

Once again, the goal here was only to prove that PMMA-PMAA materials with different molar masses and compositions can somehow protect the magnesium surface from corrosion. But, based on the data on Table 2, one can speculate that the molar mass is the most important factor for the protection effectiveness (maybe there is a threshold of molar mass, above which the protection is better), and the composition controls the pattern of the film on the surface (not correlated with corrosion protection). A systematic study on these factors is necessary to confirm that and to measure the exact effect of each one on magnesium corrosion.

As cited before, a low molar mass turns the material not only more soluble but also increases the rate of solubilization thus speeding up the disassemble of the film. Higher molar mass polymers present more chain entanglement and the dissolution kinetic is heavily controlled by chain disentanglement ${ }^{22}$, so the copolymers with high molecular weight tend to stay on the surface and protect the surface longer, as observed here.

Magnesium materials to be applied in biological system usually must keep their properties longer than a few hours. Even though the goal of this work is only to produce a proofof-concept and not a final biomaterial product, in Figure 4 the hydrogen evolved from a coated sample is depicted within a period of days. The results of the uncoated sample are shown for comparison. The hydrogen evolved from the coated one in approx. 4 days $\left(\sim 5 \mathrm{~mL} / \mathrm{mm}^{2}\right)$ is less than what is evolved by the uncoated one in less than 6 hours $\left(\sim 6,5 \mathrm{~mL} / \mathrm{mm}^{2}\right)$.

Thus, results presented here indicate the potential of PMMA-co-PMMA, a very simple polymer material to be obtained, as a corrosion reducer for magnesium-based alloys to be applied in biological systems. The amount of copolymer employed to achieve a considerable protective effect is very low (maximum of $6 \mu \mathrm{g} / \mathrm{mm}^{2}$, Figure 3 ) what minimizes the risk of toxicity. Also, the human renal filtration threshold is considered to be in the range of $30-50 \mathrm{kDa}^{18}$ and three out of 5 copolymers studied here are below that limit, so that they are not supposed to accumulate in the human body. Further systematic study of the materials and procedures proposed here, including biological tests, can lead to polymer-coated 
Table 2. Copolymers selected parameters.

\begin{tabular}{ccccc}
\hline Material & Hydrophobic index* & Mn (kDa, Table 1) & $\begin{array}{c}\text { Surface Pattern } \\
\text { (Figure 1) }\end{array}$ & Corrosion protection** \\
\hline $95: 05$ & $95 \%$ & 71.2 & Smooth & Best \\
\hline $92: 08$ & $92 \%$ & 29.8 & Smooth & Best \\
\hline $90: 10$ & $90 \%$ & 5.30 & Smooth/Alveolar & Worst \\
\hline $87: 13$ & $87 \%$ & 5.33 & Alveolar & Better \\
\hline $85: 15$ & $85 \%$ & 10.6 & Alveolar & Best \\
\hline
\end{tabular}

* initial MMA content before polymerization; ** based on hydrogen evolution tests

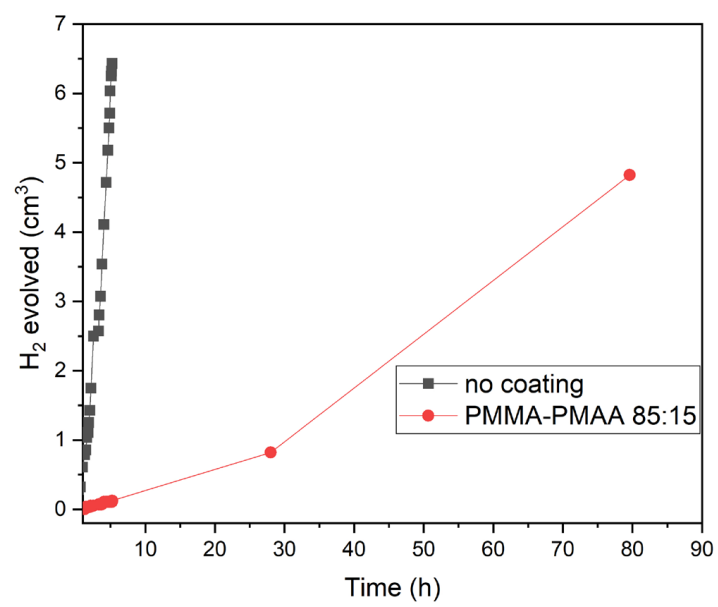

Figure 4. Hydrogen evolution during long time test. Sample coated with PMMA-PMAA 85:15 and uncoated are shown. Lines are to guide the eyes only.

magnesium materials useful for biomedical and/or other purposes.

\section{Conclusions}

Random copolymers of PMMA and PMAA were able to form polymer films on the surface of metallic magnesium by simply immersing them into a THF solution. The films are evident on SEM images and were able to protect the magnesium samples against corrosion in aqueous medium ( $\mathrm{NaCl} 0.9 \%)$.

All materials adsorbed to the magnesium surface, yielding a minimum density of around $3 \mu \mathrm{g}$ per $\mathrm{mm}^{2}$.

One material, PMMA-PMAA 90:10, the one with the lowest molar mass average, has shown a worse performance that the others concerning the corrosion protection by $\mathrm{H}_{2}$ evolution, even though it decreased the hydrogen evolution by $80 \%$ in $5 \mathrm{~h}$ compared to the uncoated sample. The other 4 materials tested showed better performance and suppressed the $\mathrm{H}_{2}$ evolution by nearly $100 \%$ within $6 \mathrm{~h}$. Molar mass seems to be the most important factor for corrosion protection effectiveness: materials above $10.6 \mathrm{kDa}$ ( 3 materials) showed better protection than the others ( 2 materials) based only on hydrogen evolution tests. Long term test showed corrosion suppression for more than $75 \mathrm{~h}$. The protection procedure proposed here has shown a good potential to control magnesium corrosion in saline aqueous media.

\section{Acknowledgements}

This study was financed in part by the Coordenação de Aperfeiçoamento de Pessoal de Nível Superior - Brasil (CAPES) - Finance Code 001. FHF acknowledges FAPESP (grant 2013/08166-5) and CNPq (grant 457733/2014-4). BXF acknowledges CNPq (grant 142337/2019-6).

\section{References}

1. Witte F. The history of biodegradable magnesium implants: A review. Acta Biomater. 2010;6:1680-92.

2. Zhang E, Yin D, Xu L, Yang L, Yang K. Microstructure, mechanical and corrosion properties and biocompatibility of Mg-Zn-Mn alloys for biomedical application. Mater Sci Eng C-Biomimetic Supramol Syst. 2009;29(3):987-93.

3. Zomorodian A, Garcia MP, Moura E, Silva T, Fernandes JCS, Fernandes $\mathrm{MH}$, et al. Corrosion resistance of a composite polymeric coating applied on biodegradable AZ31 magnesium alloy. Acta Biomater. 2013;9(10):8660-70.

4. Li L-Y, Cui L-Y, Zeng R-C, Li S-Q, Chen X-B, Zheng Y, et al. Advances in functionalized polymer coatings on biodegradable magnesium alloys - A review. Acta Biomater. 2018;79:23-36.

5. Xu W, Yagoshi K, Koga Y, Sasaki M, Niidome T. Optimized polymer coating for magnesium alloy-based bioresorbable scaffolds for long-lasting drug release and corrosion resistance. Colloids Surf B Biointerfaces. 2018;163:100-6.

6. Kawaguchi M, Takahashi A. Polymer adsorptio at solid-liquid interfaces. Adv Colloid Interface Sci. 1992;37:219-317.

7. Agarwal S, Curtin J, Duffy B, Jaiswal S. Biodegradable magnesium alloys for orthopaedic applications: A review on corrosion, biocompatibility and surface modifications. Mater Sci Eng C. 2016;68:948-63.

8. Dhandayuthapani B, Yoshida Y, Maekawa T, Kumar DS. Polymeric scaffolds in tissue engineering application: A review. Int J Polym Sci. 2011;2011:1687-9422.

9. Hendriks JGE, Van Horn JR, Van Der Mei HC, Busscher HJ. Backgrounds of antibiotic-loaded bone cement and prosthesisrelated infection. Biomaterials. 2004;25(3):545-56.

10. Jin W, Hao Q, Peng X, Chu PK. Enhanced corrosion resistance and biocompatibilty of PMMA-coated ZK60 magnesium alloy. Mater Lett. 2016;173:178-81.

11. Majumder O, Bankoti AKS, Kaur T, Thirugnanam A, Mondal AK. The influence of silane and silane-PMMA coatings on the in vitro biodegradation behavior of AE42 magnesium alloy for cardiovascular stent applications. RSC Advances. 2016;6(109):107344-54.

12. Fournier V, Marcus P, Olefjord I. Oxidation of magnesium. Surf Interface Anal. 2002;34(1):494-7.

13. Sezer N, Evis Z, Kayhan SM, Tahmasebifar A, Koç M. Review of magnesium-based biomaterials and their applications. Journal of Magnesium and Alloys. 2018;6(1):23-43.

14. Zhang E, Yin D, Xu L, Yang L, Yang K. Microstructure, mechanical and corrosion properties and biocompatibility of $\mathrm{Mg}-\mathrm{Zn}-\mathrm{Mn}$ alloys for biomedical application. Mater Sci Eng C. 2009;29(3):987-93. 
15. Lintuluoto M, Nakatsuji H, Hada M, Kanai H. Theoretical study of the decomposition of $\mathrm{HCOOH}$ on an $\mathrm{MgO}(100)$ surface. Surf Sci. 1999;429(1):133-42.

16. Santos T, dos Santos J, Luz AP, Pagliosa C, Pandolfelli VC. Kinetic control of $\mathrm{MgO}$ hydration in refractory castables by using carboxylic acids. J Eur Ceram Soc. 2018;38(4):2152-63.

17. Franco-Marques E, Parra J, Pelach MA, Mendez JA. Synthesis and characterization of self-curing hydrophilic bone cements for protein delivery. J Biomed Mater Res Part B. 2015;103(5):9921001.

18. Fox ME, Szoka FC, Fréchet JMJ. Soluble polymer carriers for the treatment of cancer: the importance of molecular architecture. Acc Chem Res. 2009;42(8):1141-51.
19. Polowiński S. Copolymerization of methacrylic acid with methyl methacrylate on a polyethylene glycol matrix. Eur Polym J. 1983;19(8):679-81.

20. Li F, Schellekens M, De Bont J, Peters R, Overbeek A, Leermakers FAM, et al. Self-assembled structures of PMAA-PMMA block copolymers: Synthesis, characterization, and self-consistent field computations. Macromolecules. 2015;48(4):1194-203.

21. Song G. Control of biodegradation of biocompatable magnesium alloys. Corros Sci. 2007;49(4):1696-701.

22. Miller-Chou BA, Koenig JL. A review of polymer dissolution. Prog Polym Sci. 2003;28(8):1223-70. 